\title{
Transformações na gestão da alteridade: curadoria compartilhada no Brasil
}

\author{
Juliana Gil Bahia Knopp
}

DOI 10.20396/eha.vil4.3397

Com o nascimento do saber científico e da necessidade de criação de métodos e regras para o trabalho de pesquisa, por volta do final do século XVIII, as coleções dos gabinetes de curiosidades foram adquiridas ou doadas às universidades, passando a ser organizadas a partir de propósitos científicos². Os objetos 'exóticos', produzidos pelo 'outro', não-ocidental, não-branco, e capturados pela ciência, pelo mercado da arte ou pela esfera pública de nações colonizadoras, foram, então, vistos pelo Ocidente por meio dos museus, por meio dos etnógrafos e romancistas, dos fotógrafos e também dos cineastas ${ }^{3}$.

Segundo Marlene Suano ${ }^{4}$, uma coleção, ao mesmo tempo em que retrata, em parte, o mundo a que se quer conhecer e dominar, também deixa evidente a história e a realidade da sociedade que a reuniu. Diante disso, pode-se observar que o Ocidente moderno acreditava que o passado estava se perdendo e que, de alguma forma, precisava ser preservado, justificando as práticas de colecionamento e produção de registros, ainda que da maneira colonial e muitas vezes violenta. Considerando que o Ocidente geralmente pensa o tempo de forma linear e irreversível, James Clifford ${ }^{5}$ ressalta que a reunião de objetos em coleções considerava aquilo que 'merecia' ser "guardado, lembrado e entesourado", de forma que pudessem ser protegidos do tempo e que pudessem resguardar a tradição daquelas culturas colecionadas. Clifford também alerta que o ato de "juntar, possuir, classificar e avaliar, sem dúvida, não se restringiram ao Ocidente.”6 Por outro lado, a característica singular do Ocidente foi a busca por acumular e preservar, em lugar de redistribuir e de 'permitir' a decadência natural ou histórica dos objetos. E sobre esta questão, a antropóloga Els Lagrou comenta que as peças utilizadas em rituais, pela maioria dos povos ameríndios, não são guardadas e precisam, inclusive, ser destruídas ou desmontadas, pois uma vez retiradas de seu contexto ritual, elas representam perigo e perdem seu valor e eficácia. Lagrou ainda reforça que peças para exposição e

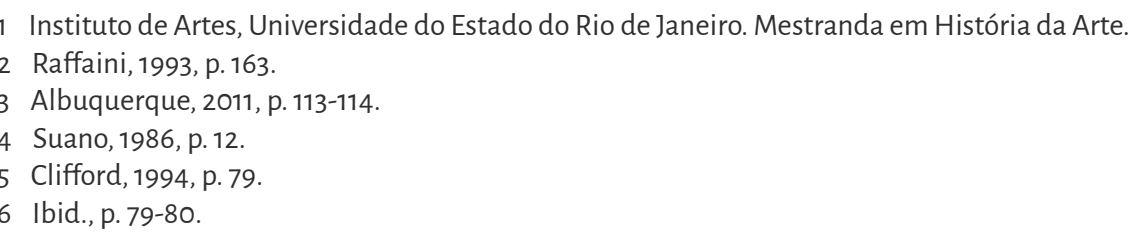


contemplação, que não são usadas ou alimentadas, não são produzidas por nenhum grupo étnico .

Para Clifford, observar os processos pelos quais o ocidente reuniu objetos em coleções se torna fundamental para compreender "como os grupos sociais que inventaram a antropologia e a arte moderna apropriaram-se das coisas exóticas, dos fatos e significados." ${ }^{8}$ Essa apropriação do mundo, de forma ordenada e classificada, que resulta nas coleções, na opinião de Susan Stewart ${ }^{9}$, cria a ilusão de uma adequada representação do mundo, que desconsidera os contextos daqueles objetos. Estes, então, tornam-se metonímia etnográfica para a cultura aos quais pertencem. Neste sentido, o colecionar e o expor, da forma como vimos apresentado, participam de forma crucial da formação da identidade ocidental ${ }^{10}$.

Uma vez que a pesquisa científica passou a ser realizada, tratada e explorada dentro de museus etnográficos, cresceram os debates em torno da instituição, como, por exemplo, sua atuação para com a sociedade, sua arquitetura, sua ambientação ou mesmo o seu espaço expositivo. Naquele momento, havia um intuito de reformulação dos grandes museus já existentes. E estas discussões tiveram dificuldades de causar transformações nos museus já há mais tempo estabelecidos, porém, foram importantes para os novos museus que foram surgindo ao longo do século $X X^{11}$.

Quando os estudos pós-coloniais começaram a surgir, na segunda metade do século XX, colocando em xeque visões e conceitos eurocêntricos oriundos do colonialismo, "o outro" - não europeu, não-branco -, marginalizado, periférico, passou a ser adotado como referência para o processo de desconstrução da herança colonialista do Terceiro Mundo. A história única, de perspectiva eurocêntrica, passou a ser, desde então, problematizada, questionada e reescrita. Conforme nos apresenta Stuart Hall12, desde o final do século XX, as sociedades modernas vêm lidando com questões acerca da identidade cultural. Os grandes avanços observados na teoria social e nas ciências humanas, juntamente com as lutas feministas, causaram um impacto na concepção até então estabelecida sobre o sujeito - de identidade única e estável. O sujeito pós-moderno, que surge a partir de todo esse processo de mudanças, carrega consigo uma identidade aberta, contraditória, inacabada e fragmentada.

Seguindo essa lógica de desconstrução da herança colonialista, os museus também pas-

\footnotetext{
7 Lagrou, 2009, p. 65.

8 Clifford, 1994, p. 73

9 Stewart, 1984 apud Clifford, 1994

10 op.cit., p. 72.

11 Suano, 1986, p. 42-46.

12 Hall, 2005
} 
saram por um movimento de renovação de seu cenário político-cultural. O modo de ser museu e de realizar exposições sobre 'o outro', até então, apresentava culturas nativas a partir da narrativa do colonizador-ocidental e de forma exótica e espetacularizada. A crítica pós-colonial impactou as instituições de tal forma que museus de arte passaram a exibir objetos etnográficos a partir de perspectivas formalistas e, por sua vez, obras de arte ocidental também experimentaram exibições contextualizadas histórica e culturalmente. Na primeira metade do século XX, muitos objetos 'exóticos', 'primitivos' ou 'arcaicos' começaram a ser vistos como Arte, sendo 'reclassificados' como 'Arte Primitiva'. E a estética modernista estreitou laços com essa 'categoria de arte primitiva'”3.

Com o novo contexto despontado, ao final do século XX, formado pela globalização - com suas raízes na modernidade ${ }^{14}$, - "A modernidade é inerentemente globalizante"15 - , pelos estudos pós-coloniais, pelas propostas de uma antropologia da arte e pelo advento da arte contemporânea, o movimento que buscava aproximar a arte indígena da arte ocidental para, então, legitimá-la enquanto arte, foi posto em xeque. A premissa de que a arte indígena seria somente aquilo que pudesse ser coletado e exposto no espaço do museu, com base em conceitos ocidentais, perde sua força e os antropólogos passam a constatar, nas situações e nas práticas, também um caráter estético que as gerações anteriores sequer pretendiam compreender como expressão artística ${ }^{16}$.

No Brasil, a partir dos anos 70, os estudos pós-coloniais passam a refletir um interesse sobre a história dos povos colonizados e o espaço acadêmico começa a desenvolver pesquisas neste sentido. A Constituição de 1988, por sua vez, garantiu aos indígenas o direito sobre suas terras, sobre a língua, educação e cultura ${ }^{17}$. Assim como nos campos jurídico e político, no que diz respeito ao direito à memória, também se observam movimentos importantes por parte das comunidades indígenas. E, por sua vez, as instituições de salvaguarda de seus patrimônios também acompanharam este processo. A ideia de que as sociedades ameríndias atuais podem e devem estabelecer relações com o seu passado está posta aos museus brasileiros ${ }^{18}$. A colaboração entre museus, órgãos nacionais, universidades, organizações não governamentais e as próprias associações indígenas têm contribuído para o aprimoramento das estratégias de documentação dos saberes indígenas, fortalecendo e valorizando culturalmente as comunidades.

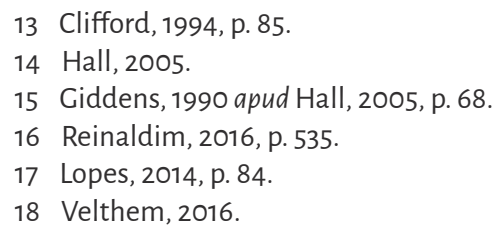


A pauta atual, no que tange a esse empoderamento de comunidades indígenas frente às suas memórias, são os 'campos' de negociação e diálogo entre pesquisadores, colecionadores, técnicos de museus e interlocutores indígenas que, nos termos atuais, devem ter acesso a tudo o que foi dito, escrito e coletado, sobre eles e entre eles. E neste cenário que reverbera nas instituições museais, provocando transformações em seus modos de gestão da alteridade, as três experiências, apresentadas a seguir, se apresentam como possibilidades para estudos de caso.

O Centro de Cultura Padre Rodolfo Lunkenbein e a repatriação de objetos Bororo

O Centro de Cultura Padre Rodolfo Lunkenbein foi inaugurado na Terra Indígena Meruri, no estado do Mato Crosso, a partir de um diálogo iniciado no ano de 1999 entre o Museu Dom Bosco, em Campo Grande (MS), e o Museu Missionário Etnológico Colle Don Bosco, na Itália. O Museu Colle Don Bosco possui uma coleção Bororo com cerca de seiscentos objetos e é considerada a segunda maior do mundo. E o ponto de partida deste diálogo foi a ideia de se criar um mecanismo de atuação que possibilitasse ao povo Bororo redefinir sua própria cultura e possibilitar o contato daqueles que eram os descendentes dos criadores daqueles objetos que foram colecionados.

Em um primeiro momento, foram feitas cópias da documentação fotográfica disponível no museu italiano e, então, essas cópias foram trazidas para a aldeia para que fossem observadas pelos membros da comunidade. Uma atividade foi realizada na escola da aldeia, onde os alunos puderam conhecer ou reconhecer os objetos de sua etnia, com ajuda dos anciãos que foram convidados a contribuir com o processo. A partir daí, os membros da comunidade conversaram sobre a história do povo Bororo e sobre sua língua, que, durante todo o processo, se mostrou ainda bem viva. Alguns membros da comunidade ainda tiveram a oportunidade de realizar uma viagem de intercâmbio na qual visitaram o museu na Itália, onde puderam ver os objetos de sua cultura material sendo expostos fora de seu país.

A partir de todo esse processo descrito é que os Bororo demonstraram desejo de recuperar sua história e os objetos de sua cultura material. O primeiro passo nesta direção foi a criação do Centro de Cultura na aldeia. O nome do Centro foi escolhido pelos próprios Bororo, que quiseram homenagear o Padre Rodolfo, morto por fazendeiros no ano de 1976 numa chacina que também vitimou Simão Bororo, membro da aldeia. Uma observação importante quanto ao nome dado ao espaço é que os Bororo rejeitaram a palavra Museu, pois, para eles, "este nome assume o significado de 'morte', 'clausura', o lugar onde os seus objetos culturais perdem a força e morrem para que os 
brancos os reconheçam como vencidos. ${ }^{19}$ Os Bororo também homenagearam Simão Bororo, dando o seu nome à Biblioteca que faz parte do Centro de Cultura.

Dentro do Centro de Cultura, os membros da comunidade construíram uma aldeia em miniatura, aos moldes de uma aldeia tradicional, com todas as características, técnicas e tradições dos Bororo. Além disso, a organização espacial da aldeia tradicional é que orienta os conceitos das exposições do Centro de Cultura e os membros Bororo cuidam da curadoria do espaço, com ajuda de professores envolvidos no projeto. Os Bororo produziram objetos rituais, vestimentas e acessórios para compor o Centro e as fotografias copiadas do museu italiano os ajudaram nesse processo. Os objetos produzidos são autorizados a sair do Centro de Cultura para atividades da comunidade e depois devem retornar. Para tal, os Bororo participaram de um workshop de conservação, para que aprendessem a conservar esses objetos.

Além dos objetos produzidos, o Centro de Cultura foi preparado para receber objetos que chegariam do museu italiano, por meio de um processo de repatriação. Estes raros objetos, que saíram do Brasil por volta de 1925, especificamente, foram acomodados em uma vitrine especial construída no Centro e não se pode manuseá-los, devido ao seu quase um século de existência e à sua importância histórica. "Hoje o Centro de Cultura Padre Rodolfo Lukenbein tornou-se referência de revitalização cultural para outras etnias que, depois de o visitarem ou ouvirem comentários a respeito das atividades desenvolvidas ali, passaram a querer a construção de centros culturais em suas aldeias [...]."20

\section{A exposição Karajás: Plumária e Etnografia}

A exposição Karajás: Plumária e Etnografia foi realizada pelo Museu Nacional no ano de 2012 e exibiu objetos da cultura material desta etnia que habita as margens do Rio Araguaia, nos estados de Coiás e Tocantins. Entre os objetos exibidos, estavam os aruanãs, que fazem parte de um complexo ritual de mesmo nome, que envolve iniciação masculina, práticas culturais ligadas aos mortos, gênero, corpo, recursos alimentares e produção de objetos materiais ${ }^{21}$. No ritual, que ocorre durante a alta do Rio Araguaia, os herdeiros de aruanã tem encontros com seus ancestrais que habitam planos cosmológicos e, então, entoam cânticos e dançam de forma sincronizada, em duplas,

19 Braga; Carvalho; Silva, 2004, p. 283.

20 Braga; Carvalho; Silva, 2004, p. 285

21 Lima Filho, 2017, p. 492. 
pela aldeia.

Na ocasião da exposição, os Karajás foram convidados a participar da abertura e quando o grupo se deparou com a vitrine onde estavam sendo expostos os aruanãs, imediatamente demonstraram desconforto. O motivo do desconforto é que, para a etnia, exibir os aruanãs causaria sérios danos à vida cotidiana das aldeias na medida em que colocaria sob risco o segredo guardado pelos homens. No cotidiano da aldeia, existem interdições e proibições que delimitam a circulação de mulheres e crianças em caminhos e espaços autorizados apenas para homens. É neste sentido que o segredo dos homens estaria ameaçado, uma vez que não se pode controlar o acesso das mulheres e crianças ao que é exposto no museu ou em fotografias divulgadas na internet, ainda que esses espaços os tratem como objetos inanimados.

Após o episódio da abertura da exposição, os Karajás solicitaram ao Museu Nacional que os aruanãs fossem retirados da exposição e também os seus registros fotográficos disponíveis no site da instituição. O museu atendeu ao pedido do grupo e , a partir daí, a questão dos aruanãs que foram colecionados e estão sob a guarda de museus foi discutida entre lideranças indígenas.

No que diz respeito aos objetos etnográficos, de uma maneira geral, ainda resiste uma perspectiva a partir da qual são tratados como objetos científicos, inertes ou mesmo 'arte indígena', 'desconsiderando' os contextos e tradições rituais da etnia pertencente. Por outro lado, esses povos tradicionais vem se articulando de modo a reivindicar seu lugar de fala e sua autoridade enquanto herdeiros desses objetos produzidos por seus antepassados. A narrativa unilateral predominante a do colonizador vendo sendo substituída pelo diálogo entre "coleções e colecionados", ou seja, entre povos nativos e instituições.

\section{A exposição Dja Guata Porã: Rio de Janeiro indígena}

A exposição Dja Guata Porã: Rio de Janeiro indígena", realizada pelo Museu de Arte do Rio em 2017, em sua gênese, já se constrói compartilhada. Nesta exposição, os indígenas compartilharam da curadoria, ao mesmo tempo, produziram objetos para serem expostos. O museu, por sua vez, não trabalhou com uma coleção específica, e sim propôs uma autorreflexão no sentido de utilizar seus recursos e sua visibilidade para fazer ver a presença indígena no estado do Rio de Janeiro e também o interesse desses indígenas pelo espaço ${ }^{22}$.

22 Vieira, 2019, p. 232. 
O projeto da exposição foi conduzido por um gesto curatorial coletivo de Clarissa Diniz, José Ribamar Bessa Freire, Pablo Lafuente e Sandra Benites, que é Guarani e mestre e doutoranda em Antropologia Social. O início dos trabalhos se deu com encontros com indígenas residentes no Rio de Janeiro para apresentação da proposta da exposição. A partir daí, foram realizados encontros semanais entre a equipe do Museu e os interlocutores indígenas. As primeiras reuniões identificaram quatro núcleos representativos: "os Guarani, enquanto povo aldeado; os Puri, que estão no processo de ressurgência; os Índios em Contexto Urbano, que representam indígenas de diferentes etnias que residem na cidade; e os Pataxó, residentes no município de Paraty que buscam demarcação da terra." $^{23}$

As obras produzidas pelos indígenas para a exposição foram comissionadas e "pressupõem o direito de propriedade intelectual daqueles que as produziram e não foram diretamente incorporadas ao acervo do MAR." ${ }^{24}$ Além disso, com o intuito de descontruir a narrativa já existente sobre os povos indígenas, a exposição trouxe uma proposta de temporalidade inspirada na cartilha "História Indígena", de 1996, produzida por professores índios do Acre e do Sul do Amazonas, no âmbito de um projeto desenvolvido pela Comissão Pró-Índio do Acre. A cartilha narra a história dos povos indígenas do Acre a partir de uma divisão do tempo em: tempo das malocas, tempo das correrias, tempo do cativeiro, tempo dos direitos e tempo do governo dos índios. Em Dja Guata Porã o tempo ficou dividido em: tempo da autonomia, que considera o período que precede a invasão européia, tempo da invasão, correspondente à chegada dos europeus ao território e aos primeiros movimentos de colonização durante o século XVI, tempo da usurpação, que se estende da segunda metade do século XVII até o XX, passando pelas medidas de instituição da colônia até a política indigenista, e tempo das retomadas, concentrado entre os séculos $X X$ e XXI, que apresenta o momento de organização política dos povos indígenas.

Como podemos ver em Vieira ${ }^{25}$, a fala de Pablo Lafuente na ocasião da abertura da exposição evoca a importância dessa experiência, que colocou "o indígena como participante, como alguém que construiu este discurso, construiu este percurso, construiu esta exposição [...]". E as possibilidades e desdobramentos germinados a partir de Dja Guata Porã seguem sendo vivenciados e discuti$\operatorname{dos}^{26}$. 


\section{Referências Bibliográficas}

ALBUQUERQUE, Marcos Alexandre dos Santos. O regime imagético Pankararu (tradução intercultural na cidade de São Paulo). Tese. Florianópolis: Universidade Federal de Santa Catarina, 2011.

ATHIAS, Renato; COMES, Alexandre. Coleções etnográficas, museus indígenas e processos museológicos. Recife: Editora UFPE, 2016.

BRACA, Gedley Belchior; CARVALHO, Aivone; SILVA, Dulcília Lúcia de Oliveira. Perspectivas recentes para curadoria de Coleções Etnográficas. Revista do Museu de Arqueologia e Etnologia, São Paulo, v. 14, p. 279-289, 2004.

CLIFFORD, James. Museus como zonas de contato. Tradução de Alexandre Barbosa de Souza e Valquíria Prates. Periódico Permanente, São Paulo, v. 4, n. 6, 2016.

CLIFFORD, James. Colecionando Arte e Cultura. Revista do IPHAN, Brasília, n 23, 1994.

GRUPIONI, L. D. B. Os museus etnográficos, os povos indígenas e a antropologia: reflexões sobre a trajetória de um campo de relações. In: Museu, Identidades e Patrimônio Cultural, Revista do Museu de Arqueologia e Etnologia, São Paulo, Suplemento 7, p. 21-33, 2008.

HALL, Stuart. A identidade cultural na pós-modernidade. 10. ed. Rio de Janeiro: DP\&A, 2005.

LAGROU, Els. Arte indígena no Brasil. Belo Horizonte: C/Arte, 2009.

LIMA FILHO, Manuel Ferreira. Coleção William Lipkind do Museu Nacional: trilhas antropológicas Brasil-Estados Unidos. Mana, Rio de Janeiro, v.23, n.3, p. 473-509, 2017.

LOPES, Danielle Bastos. O direito dos índios no Brasil: a trajetória dos grupos indígenas nas constituições do país. Espaço Ameríndio. Porto Alegre, v. 8, n. 1, p. 83-108, jan./jun., 2014.

RAFFAINI, P. T. Museu Contemporâneo e os Cabinetes de Curiosidades. Revista do Museu de Arqueologia e Etnologia. São Paulo, n. 3, p. 159-164, 1993.

REINALDIM, Ivair. Produção cultural indígena e história da arte no Brasil: a problemática do deslocamento/descolamento. In: Arte em Ação - XXXVI Colóquio do Comitê Brasileiro de História da Arte, 2016, Campinas. Anais do XXXVI Colóquio do Comitê Brasileiro de História da Arte. 2017, CBHA, v. 1. p. 530-539, 2016.

SILVA, Jocenaide Maria Rosseto. Do Museu como Espaço ao Museu como Lugar de Múltiplas Interlocuções: os Museus Universitários e as Coleções do Povo Bororo. Tese. São Paulo: PUC-SP, 2013.

SUANO, Marlene. O que é museu. São Paulo: Brasiliense, 1986.

VELTHEM, Lucia Hussak van. Prefácio. In: ATHIAS, Renato; COMES, Alexandre. Coleções etnográficas, museus indígenas e processos museológicos. Recife: Editora UFPE, 2016.

VIEIRA, Mariane Aparecida do Nascimento. Dja Guata Porã: o rio indígena que desaguou no MAR. Revista Horizontes Antropológicos, Porto Alegre, ano 25, n. 53, p. 227-256, jan./abr., 2019. 